\title{
Análise do Perfil dos Autores da Revista de Epidemiologia e Controle de Infecção - RECI - 2016 a 2018
}

Cassiandra Sampaio Joaquim ${ }^{1}$, Jorge Luiz Schmidt' ${ }^{1}$ Nathalia Halax Orfão², Andreia Rosane de Moura Valim¹, Lia Gonçalves Possuelo ${ }^{1}$ 1. Universidade de Santa Cruz do Sul, Santa Cruz do Sul, RS; 2. Fundação Universidade Federal de Rondônia

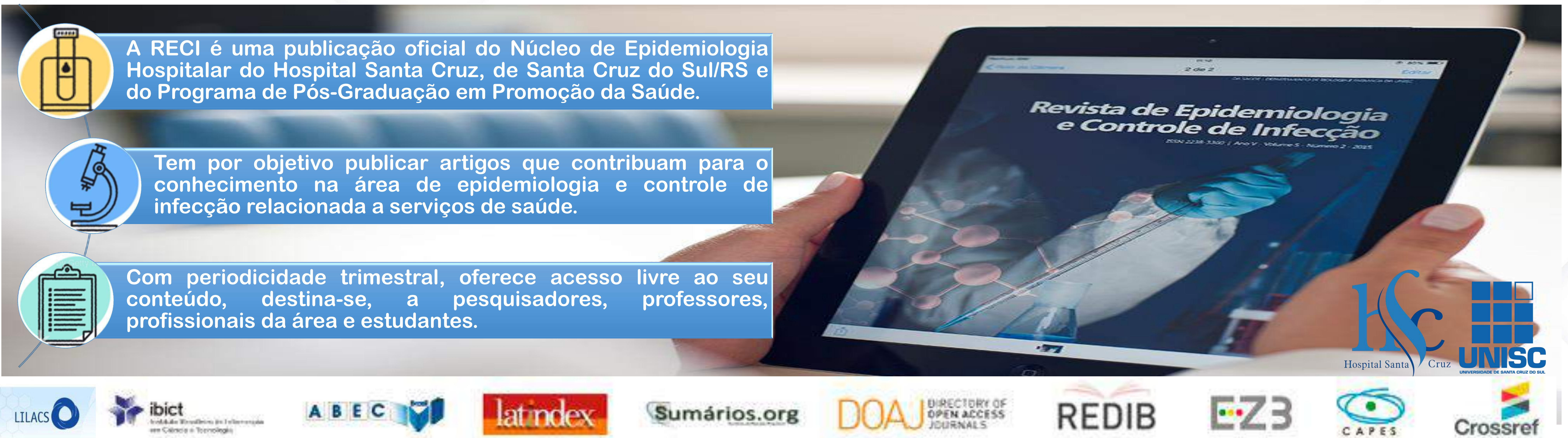

\section{Introdução}

A RECI segue o princípio de que disponibilizar gratuitamente o conhecimento científico ao público proporciona maior democratização do conhecimento.. Mas, para que tudo isso aconteça, existe uma peça chave: o autor. As normas de publicação das revistas em geral, são unânimes em afirmar como autores as pessoas que contribuíram substancialmente com o trabalho. Não basta fazer entrevistas ou coletar dados. É preciso contribuir nas ideias, na concepção do projeto, na análises dos dados e, também, cooperar na redação do manuscrito. Com o objetivo de conhecer quem são os autores que publicam na RECI, este estudo objetiva avaliar o perfil desses autores que publicaram no período de 2016 a 2018, visando aprimorar a interfaces da pesquisa, da publicação científica e dos seus autores.

\section{Metodologia}

Trata-se de um estudo descritivo retrospectivo. Os dados foram coletados, nos 12 números publicados de 2016 a 2018.
Foram incluidas informacões do primeiro e último autor de artigos originais e de artigos de revisão. As variáveis instituição de vínculo, região, nome do programa de pós-graduação de vínculo e o conceito, foram coletados na Plataforma Lattes e na Plataforma Sucupira.

Todos os dados foram tabulados e analisados utilizando o software Excel $\mathrm{TM}^{\mathrm{M}}$. As análises descritivas foram apresentadas como frequências e números absolutos.
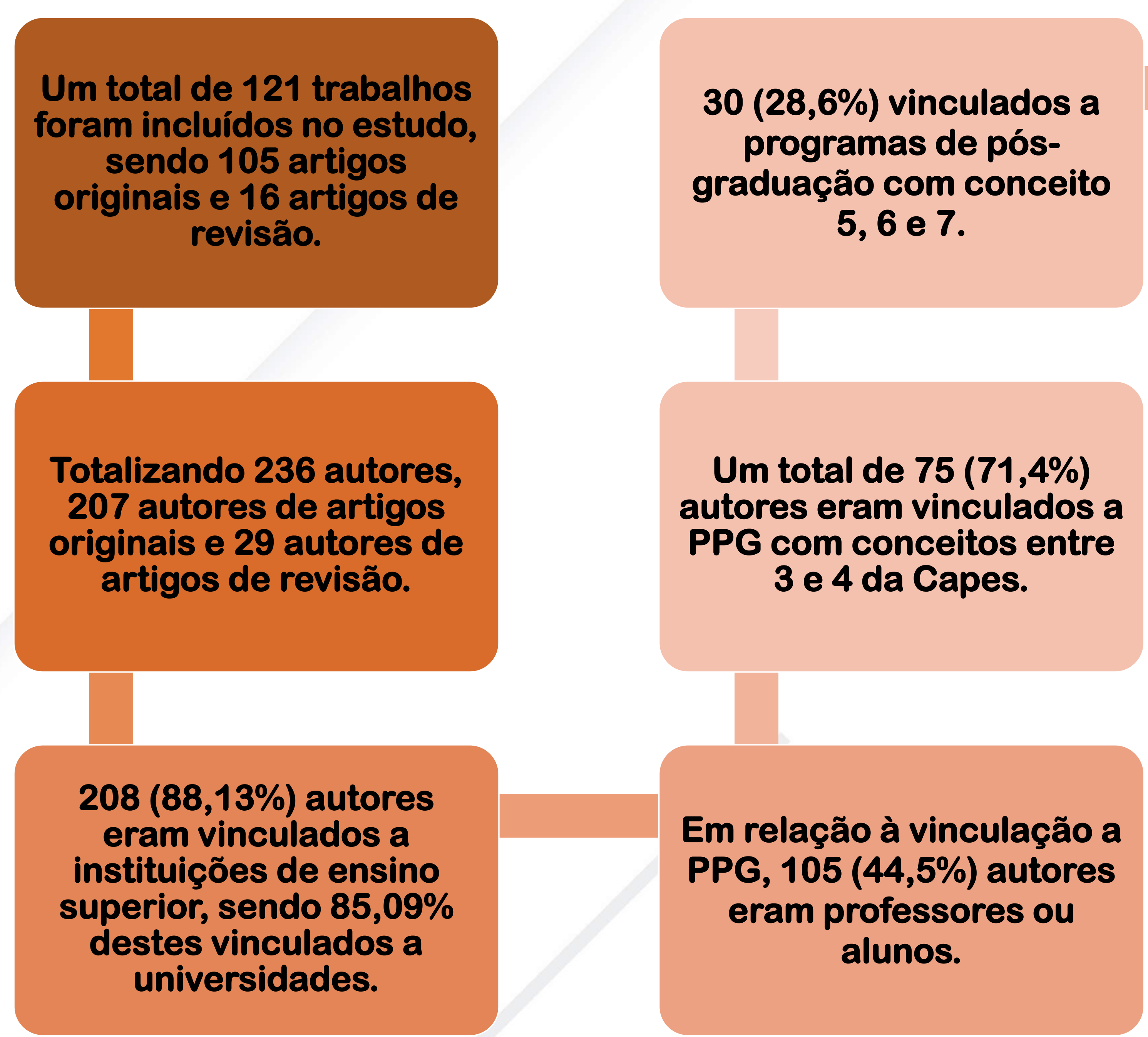

\section{Resultados}

\section{Conclusões}

A partir dos dados coletados, é possível descrever o perfil dos autores da RECI no triênio 2016/2018 como um perfil de pesquisadores que têm procurado publicar seus manuscritos em revistas de acesso aberto, e que, a maioria são autores vinculados a universidades, sendo mais de $40 \%$ com afiliação a PPG com conceito 3 e 4 . Além disso, a Região Sul destaca-se com o maior número de manuscritos publicados na RECI no período analisado. Sendo assim, e a partir destes dados a equipe editorial poderá direcionar as estratégias de divulgação do periódico assim como desenhar estratégias para qualificar o mesmo, valorizando os autores e as referências mais atuais do campo científico.

\section{Referências}

ROCHA, E. M. P. \& Ferreira, M. A. T. (2004). Indicadores de ciência, tecnologia e inovaç̃o: mensuração dos sistemas de CTel nos estados brasileiros. Ciência da Informação, Brasilia, 33 (3), 61 - 68. 